\title{
Drawing from justice theories to support targets of online harassment
}

new media \& society

I-23

(C) The Author(s) 2020

Article reuse guidelines: sagepub.com/journals-permissions DOI: $|0.1| 77 /|46| 4448209|3| 22$ journals.sagepub.com/home/nms

(\$SAGE

\author{
Sarita Schoenebeck (D), Oliver L Haimson \\ and Lisa Nakamura \\ University of Michigan, USA
}

\begin{abstract}
Most content moderation approaches in the United States rely on criminal justice models that sanction offenders via content removal or user bans. However, these models write the online harassment targets out of the justice-seeking process. Via an online survey with US participants $(N=573)$, this research draws from justice theories to investigate approaches for supporting targets of online harassment. We uncover preferences for banning offenders, removing content, and apologies, but aversion to mediation and adjusting targets' audiences. Preferences vary by identities (e.g. transgender participants on average find more exposure to be undesirable; American Indian or Alaska Native participants on average find payment to be unfair) and by social media behaviors (e.g. Instagram users report payment as just and fair). Our results suggest that a one-sizefits-all approach will fail some users while privileging others. We propose a broader theoretical and empirical landscape for supporting online harassment targets.
\end{abstract}

\section{Keywords}

Content moderation, fairness, gender, harassment, justice, race, social media

\section{Introduction}

Social media sites have developed a set of complex processes for responding to online harassment (Pater et al., 2016). These processes, which are largely developed within US-based companies and cultures, focus on determining whether content violates

\section{Corresponding author:}

Sarita Schoenebeck, University of Michigan, 105 S State Street, Ann Arbor, MI 48I09-1382, USA.

Email: yardi@umich.edu 
community guidelines, and if so, whether and how to sanction offenders who have violated those guidelines. For example, content that discriminates against another person or group may be removed and the offender may be warned or outright banned (Bradford et al., 2019). On the contrary, content may be offensive to some users but deemed not in violation of community guidelines and thus left in place (Gillespie, 2018; Roberts, 2019). Regardless of outcome, targets of offensive or harmful content receive little or no notification during the content moderation process, preventing them from experiencing acknowledgment or reparation of the harms they may have experienced. Indeed, "processes optimized solely for stopping harassment are unlikely to address the larger impact of the harassment on the targeted user" (Matias et al., 2015). Furthermore, people from protected social groups (e.g. based on gender, sex, race, religion, or disability) are more likely to be targets of harassment on social media, perpetuating and magnifying injustices they experience in their lives (Duggan, 2017). These individuals tend to be undercompensated for their online labor (Postigo, 2016) and expend disproportionate work to be included online (Ahmed, 2012).

Content moderation approaches mirror principles from criminal justice systems in the United States, which focus on punishing offenders rather than restoring justice to victims (Bobo and Thompson, 2006; Cole, 1999; Wenzel et al., 2008). Criminal justice theories propose that crime should be met with proportionate punishment (e.g. ranging from fines to imprisonment). As social media sites have grown dramatically in scale, they have adopted criminal justice approaches to regulation where people who violate rules or norms are warned or removed from the community (Matias et al., 2015; Pater et al., 2016). This work builds on a growing movement in the United States that recognizes the criminal justice system's limitations in supporting targets of an offense. While other studies have examined harassment perpetrators' (Munger, 2017) and harassment reporters' (Matias et al., 2015) experiences, this study was designed to prioritize the voices of the targets themselves. This research critically examines social media sites' responses to online harassment and lays a path for integrating justice into the governance process.

\section{Online governance}

Online governance models rely on a combination of policies, norms, tools, administrators, workers, and computation. Governance models can be either top-down (in which harassment policies and moderation are imposed by the platform), bottom-up (in which users decide on and impose their own rules and moderation strategies), or a combination of the two (Bradford et al., 2019). Top-down approaches to moderation typically seek to position sites as neutral, displaying standardized guidelines that "perform, and therefore reveal in oblique ways, how platforms see themselves as public arbiters of cultural value" (Bradford et al., 2019; Caplan, 2018; Gillespie, 2018; Pater et al., 2016). However, content moderation decisions are invisible to users, allowing sites to disguise the power they wield over the process (Gillespie, 2010; Roberts, 2019). While most people feel social media companies have a responsibility to remove offensive content from their platforms, few have confidence in companies to determine what offensive content should be removed (Laloggia and Inquiries, 2019). In contrast, bottom-up approaches rely on volunteer moderation practices that require extensive uncompensated labor from volunteers (Postigo, 
2016). On Reddit and Twitch, for example, subreddits or channels rely on volunteer moderators to establish and enforce site policies and norms (Matias, 2019; Seering et al., 2019; Wohn, 2019), and strategies for handling harassment include educating, sympathizing, shaming, humor, and blocking (Cai and Wohn, 2019). Volunteer moderation is often buttressed by automated bots or systems (e.g. Chandrasekharan et al., 2019) that support moderation demands at scale. Moderation is also performed by users themselves, either individually via report options or en masse (e.g. third-party blocklists; Jhaver et al., 2018).

This work aims to radically reconsider how social media sites should support targets of online harassment. We focus on top-down governance to encourage broader and more equitable governance practices from companies who have a responsibility to support online harassment targets. Drawing from justice theories, our goal is to uncover approaches that recognize power differentials and are responsive to people with a wide range of abilities, identities, and preferences. Such approaches acknowledge that designing for people without power requires designing for everybody, by seeking to eradicate those systems of power (The Combahee River Collective Statement, n.d.). While regulatory approaches can increase social media companies' responsibility to their users (e.g. rights to privacy, right to not be discriminated against), such approaches may not inspire trust or confidence from targets of online harassment given that US laws and criminal justice systems have historically been complicit with institutions like slavery and sexism (Bobo and Thompson, 2006; Cole, 1999).

\section{Theories of justice and online responses}

On social media, targets of online harassment have few opportunities to experience visibility or reparation. Even if offensive content is removed from the site or an offender is banned from the site, the target can experience harms that feel isolating and invisible. While the criminal justice system has a strong foothold in US justice systems (Cole, 1999; Wenzel et al., 2008), the past few decades have seen increased interest in theories of justice, including restorative justice, racial justice, and social justice, that prioritize rehabilitation and reparation rather than punishment (Bell, 2008; Jackson, 2013; Wenzel et al., 2008).

Restorative justice is concerned with mediation processes that mend conflict between an offender, a victim, and the community, often with the involvement of facilitators (Braithwaite, 1999; Wenzel et al., 2008; Zehr, 2015). Restorative justice requires that offenders acknowledge wrongdoing, accept responsibility for their actions, and express remorse, typically via an apology. However, apologies currently play little role in criminal justice procedures in the United States. Bibas and Bierschbach (2004) note, "Our criminal justice system works as a speedy assembly line: It plea bargains cases efficiently and maximizes punishment for the limited resources available. This assembly line leaves little room for remorse and apology." In addition, apologies have been discouraged in legal proceedings because they may invoke admissions of responsibility or blameworthiness (Scher and Darley, 1997).

Theories of racial and economic justice acknowledge the systematic injustices and inequities communities have experienced via lack of access to employment, education, housing, and other rights (Bell, 2008; Cole, 1999; Fallon and Weiler, 1984; Jackson, 
2013). Most views toward racial justice advocate for deliberate systems and support to promote racial equity rather than simply removing discrimination. Ahmed (2012) notes, "Describing the problem of racism can mean being treated as if you have created the problem, as if the very talk about division is what is divisive." Indeed, critical race theory grew out of the need to understand the differential forms of oppression that apply to multiple identities such as race, class, and gender: laws were not designed to treat everyone equally, and any just application of the law must acknowledge this and work to align laws to this reality. Proponents of reparations have called attention to the generational downstream effects of slaves' inability to earn wages for their work or acquire literacy and education (Coates, 2014; Nelson, 2016). They also have called attention to long legacies of trauma and grief across generations as a result of displacement and genocide (Brave Heart and DeBruyn, 1998). An economic justice approach argues that people should be given what allows them to lead a fruitful life, including payment for work that is done (Jackson, 2013).

Racial and economic justice overlap with the concept of social justice, which Rawls (2009) popularized as the distribution of benefits and burdens across individuals and social groups. More contemporary lens have critiqued Rawls' "veil of ignorance" approach which overlooks individual identities and experiences. Instead, social justice scholars argue identity should be central to interpretations of justice, which acknowledge identity as complex and fluid (e.g. what it means to be an immigrant shifts based on how immigrants are treated) (Clayton and Opotow, 2003). Furthermore, social justice advocates for spaces for individuals to participate safely within a shared set of values.

\section{Measuring justice}

Justice has sometimes been conflated with the concept of fairness and is often measured using the language of fairness in surveys. For example, distributive justice considers whether benefits are distributed fairly across individuals and is typically measured with questions about fairness (Sunshine and Tyler, 2003; Tyler, 1994). Procedural justice (which is sometimes referred to as procedural fairness) considers whether processes were perceived as fair, independent of outcome (Sunshine and Tyler, 2003; Tyler, 1994). Consistent with procedural justice theory, increased transparency in content moderation explanations increases perception that a decision was fair (Jhaver et al., 2019). Facebook is working to increase procedural justice in its content moderation; however, it is largely focused on how to increase perceptions of fairness among offenders (Bradford et al., 2019). In contrast, our work seeks to promote justice in outcomes for harassment targets.

Justice acknowledges structural power differentials and seeks to dismantle them, whereas fairness maintains power differentials, because it locates the source of problems within individuals or technologies (D'Ignazio and Klein, 2020). Hoffmann (2019) argues that the concept of fairness falsely attributes harm to individuals instead of systemic and contextual problems. That argument has been recognized by some computer scientists, who acknowledge the limitations of fairness in mathematical representations because of the values and politics they embed (Barocas et al., 2019). Fairness further falls short because racism, sexism, and various forms of discrimination are fundamentally different from other kinds of rule violations. 
Thus, while social media sites' enforcement of rules about copyright violation and appropriate use may enact justice in appropriate ways, when these same enforcement mechanisms are used to address harmful behaviors like hate speech, users feel unseen, unheard, and doubly harmed (Citron, 2014). Hoffmann and Jonas (2016) call for a more expansive notion of justice that exposes how technology companies' power can create hostile environments for vulnerable or otherwise disadvantaged populations, with little legal or regulatory oversight (Citron, 2014).

Our survey measured three variables — justice, fairness, and desirability — of responses to online harassment. We developed these measures by first conducting a preliminary study to understand participants' perceptions of justice and fairness in response to online harassment. Our preliminary study paired an online experiment with a free response survey, and found that participants perceived banning or blocking users as just responses, and banning users or legal regulation as fair responses. It also showed that favorability toward justice and fairness of social media governance can vary by identity, a theme the current study develops further. In terms of desirability, what is desirable may not necessarily align with what is just or fair, and vice versa. Rawls (2009) proposed that justice principles should order a society stably over time because people will develop a desire to act in accordance with those principles. In practice, of course, society does not converge so easily. In the context of social media regulation, we define fairness as the correct enforcement of previously stated rules that a user has violated. In contrast, we view justice as the effective remediation of harms arising from interpersonal conflict, prejudice, and harassment. Justice centers the experiences and perspective of the person who suffered harm. Finally, we define desirability as simply what users find desirable as an outcome.

\section{Hypotheses and research questions}

Traditional approaches to responding to online harassment (i.e. removing content, banning users) are the status quo, but people may value alternative approaches that enact justice in more holistic and comprehensive ways (e.g. apology, mediation, payment). Thus, we ask,

RQ1: Are there differences in attitudes toward perceived (a) justice, (b) fairness, and/or (c) desirability of traditional versus alternative actions taken by social media sites?

Traditional criminal justice systems in the United States have perpetuated discrimination and inequities toward people from marginalized identities, and these injustices are perpetuated online. We investigate whether people from non-dominant identities (e.g. racial minorities, transgender people) prefer alternative approaches to the criminal justice model, and conversely, whether people from dominant identities prefer the status quo.

H1a: Non-dominant social groups will be more favorable toward perceived (a) justice, (b) fairness, and/or (c) desirability of alternative actions taken by social media sites, as opposed to traditional actions. 
And the corollary,

H1b: Dominant social groups will be more favorable toward perceived (a) justice, (b) fairness, and/or (c) desirability of traditional actions taken by social media sites, as opposed to alternative actions.

Identity attributes (e.g. race, gender, political views, socioeconomic class, and age) have all influenced how people experience justice through social, technological, and legal systems in the United States. Here, we examine the relationship between identity and attitudes toward how social media sites should respond to online harassment.

RQ2: Is racelethnicity associated with attitudes toward perceived (a) justice, (b) fairness, and/or (c) desirability of actions taken by social media sites?

RQ3: Is gender associated with attitudes toward perceived (a) justice, (b) fairness, and/or (c) desirability of actions taken by social media sites?

RQ4: Is political orientation associated with attitudes toward perceived (a) justice, (b) fairness, and/or (c) desirability of actions taken by social media sites?

RQ5: Is socioeconomic class associated with attitudes toward perceived (a) justice, (b) fairness, and/or (c) desirability of actions taken by social media sites?

RQ6: Is age associated with attitudes toward perceived (a) justice, (b) fairness, and/ or (c) desirability of actions taken by social media sites?

Social media sites have different rules and norms that govern appropriate behavior. Here we ask whether frequency of use on six different major platforms influences attitudes toward how social media sites should respond to harassment.

RQ7: Is frequency of use associated with attitudes toward perceived (a) justice, (b) fairness, and/or (c) desirability of actions taken by social media sites?

Social media sites evaluate whether content was in violation of community guidelines in isolation, which prevents them from recognizing sustained harassment over time (Blackwell et al., 2017; Duggan, 2017; Massanari, 2017). Here we examine whether past experiences of being targets or perpetrators of harassment, or supporters or targets of harassment, influence attitudes toward how social media sites should respond to that harassment.

RQ8: Are prior experiences of being harassed or harassing others on social media associated with attitudes toward perceived (a) justice, (b) fairness, and/or (c) desirability of actions taken by social media sites?

Finally, orientations toward justice could influence preferences for actions sites take. Some actions might be perceived as more fair in terms of process (procedural justice) or outcome (distributive justice). 
RQ9: Are orientations toward procedural or distributive justice associated with attitudes toward perceived (a) justice, (b) fairness, and/or (c) desirability of actions taken by social media sites?

\section{Overview of methods}

This study was deemed exempt by our institution's ethics review board. Participants completed an online consent form. We pre-registered research questions and hypotheses on the Open Science Foundation ${ }^{1}$ before data collection began (RQ9 was added after).

\section{Survey development}

We used the language of "aggressive or hostile on social media" as proxies for "online harassment." Both terms are susceptible to response bias, but "online harassment" has been used in mainstream media in socially and politically charged contexts and may be more susceptible to a variety of biases. We developed the alternative language via a focus group then pilot tested the language iteratively. We use "aggressive or hostile" when referring to our instruments, and related language like harassment, bad behavior, and abuse when describing general phenomena. We chose not to define justice, fairness, or desirability in the survey because they cannot be concisely defined in a survey item, and because we wanted to elicit participants' favorability to those concepts based on their own internal interpretations. As a result, participants' responses will reflect their own varied conceptualizations of what justice and fairness mean. We pre-tested the anchor "restore justice to me" with 30 online participants to confirm that they were able to interpret the phrase.

We conducted an online, anonymous survey of adults in the United States. We developed 10 items iteratively via brainstorming and discussions among the research team and pilot testing multiple times. The final survey contained two items that represent traditional actions on major platforms and the remaining eight items were novel, alternative actions not currently used by major platforms. The traditional actions reflect criminal justice theories while the alternative actions reflect a range of values embedded across criminal, racial, economic, and social justice theories. Each question contained the stem, "Imagine that a person is being aggressive or hostile to you on social media. The social media site responds by [options in Table 1]." Each of the 10 items was presented as a bipolar matrix with three rows measuring justice, fairness, and desirability.

The next section asked about prior experiences being perpetrators, targets, or supporters of targets of online harassment. We adapted scales from Sunshine and Tyler (2003) to measure participants' beliefs about procedural justice (three items) and distributive justice (three items) among social media sites. Internal consistency of the procedural justice scale was reliable with $\alpha=.84$. Distributive justice was not reliable with $\alpha=.33$, possibly because two of the questions were difficult to interpret; we used the remaining question to measure distributive justice. Finally, we asked about use of social media platforms and demographic questions. For demographics, gender, race, and sexual orientation categories were not mutually exclusive; each respondent could choose multiple options, and many fell into multiple categories (e.g. non-binary and woman). 
Table I. Potential social media site responses to online harassment.

\begin{tabular}{|c|c|}
\hline Action & Survey prompt \\
\hline \multicolumn{2}{|c|}{ Traditional social media site actions } \\
\hline Removing content & "removing the content from the site" \\
\hline Banning users & "banning the person from the site" \\
\hline \multicolumn{2}{|c|}{ Alternative social media site actions } \\
\hline Payment & "paying you and your supporters" \\
\hline Apology & "requiring a public apology from the person" \\
\hline Offender list & "adding the person to an online public list of offenders" \\
\hline Mediation & $\begin{array}{l}\text { "facilitating an online meeting including you, the person, } \\
\text { and a mediator to discuss your experience" }\end{array}$ \\
\hline Identity & $\begin{array}{l}\text { "educating the person about your identities and } \\
\text { experiences" }\end{array}$ \\
\hline Less exposure & $\begin{array}{l}\text { "allowing you to be less exposed to a wide audience on } \\
\text { the site" }\end{array}$ \\
\hline More exposure & $\begin{array}{l}\text { "allowing you to have more exposure to a large } \\
\text { audience on the site" }\end{array}$ \\
\hline Own space & $\begin{array}{l}\text { "empowering you to have a space with your own rules } \\
\text { and values" }\end{array}$ \\
\hline
\end{tabular}

\section{Recruitment and demographics}

We recruited participants via Prolific, Mechanical Turk, Positly, and word-of-mouth. Workers on MTurk had to have a Human Intelligence Task (HIT) approval rate of higher than $98 \%$, be located in the United States, and have had more than 5000 HITs approved. We compensated Prolific, MTurk, and Positly respondents \$3. Word-of-mouth respondents were given the option of receiving a \$3 Amazon gift card or donating \$3 to charity; most chose the gift card. We manually removed low quality responses and our final sample had 573 participants. The median duration to complete the survey was 7.5 minutes; the $75 \%$ quartile duration was just over 10 minutes, which confirms a median wage of more than $\$ 15 /$ hour. We recruited participants in batches to sample diverse demographics; our final sample included people who were women (45\%), non-binary $(9 \%),{ }^{2}$ transgender (15\%), custom gender (1\%, including Prefer Not to Disclose and Prefer to Self-Describe), Black or African American (21\%), Hispanic or Latino (13\%), Asian (8\%), American Indian or Alaska Native (4\%), Middle Eastern (1\%), Native Hawaiian or Pacific Islander (1\%), custom race/ethnicity $(0 \%$, including Prefer Not to Disclose and Prefer to SelfDescribe), Liberal (57\%), Conservative (18\%), and with household income less than $\$ 50 \mathrm{k}$ $(43 \%)$. Liberals are overrepresented due to targeted sampling based on other identities.

\section{Results}

To answer RQ1, we used one-way repeated-measures analysis of variance (ANOVA) with Tukey honestly significant difference (HSD) post hoc comparisons. Results are shown visually in Figure 1 and multiple comparisons are in Supplemental Materials. To test H1 and address RQ2 to RQ9, we fitted a series of linear regression models modeling 


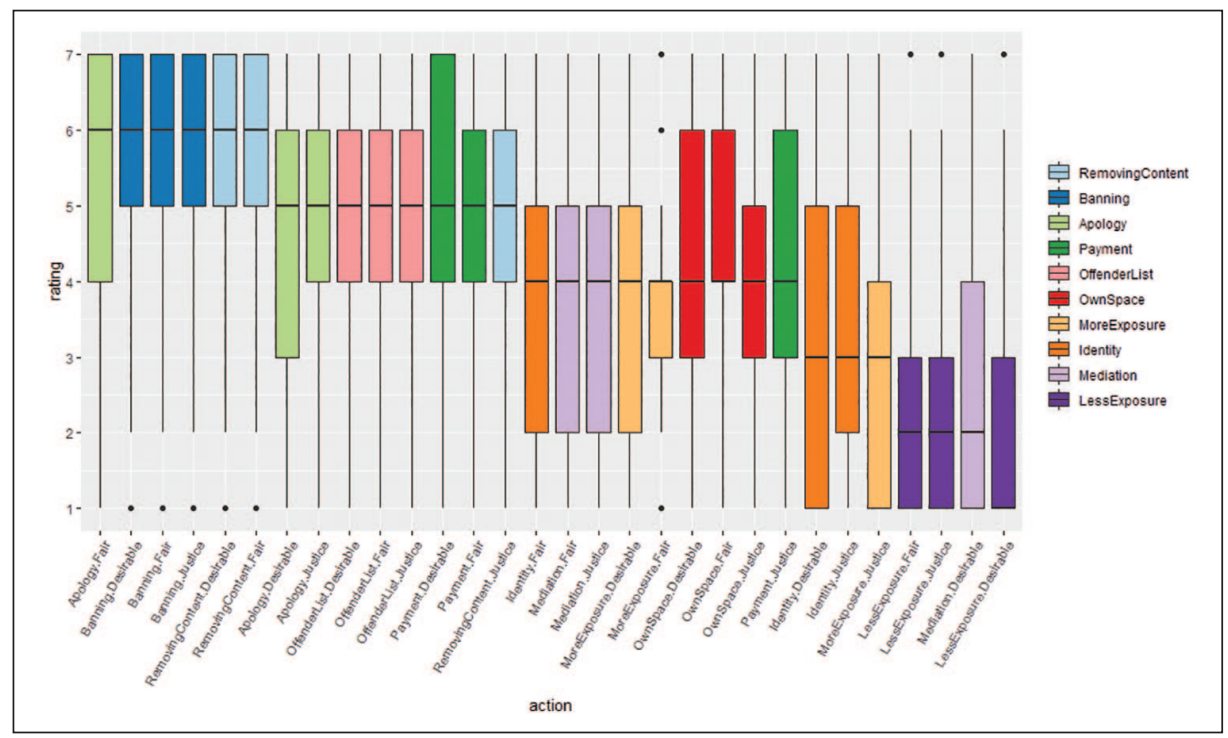

Figure I. Plot showing preferred actions social media sites can take ordered by more favored (left) to less favored (right).

preferences as the dependent variable and identity and social media uses/preferences as independent variables. Variance inflation factor (VIF) values were less than three, indicating multicollinearity was not an issue. We used Akaike's Information Criteria (AIC) to exclude independent variables that did not improve the model fit. Models are in Tables 2 to 5 and communicated via heat map using correlation coefficients in Figure 2. Reference categories are man for gender and White for race/ethnicity. Results are summarized in Table 6.

\section{Preferred actions}

Group means were statistically significantly different from one another, $F(29$, $17160)=212.6, p<0.0001$. In general, participants were significantly more likely to favor banning users (justice: $M=5.26, S D=1.67$; fair: $M=5.53, S D=1.50$; desirable: $M=5.46, S D=1.62$ ), removing content (justice: $M=4.76, S D=1.66$; fair: $M=5.21$, $S D=1.54$; desirable: $M=5.21, S D=1.64$ ), and apology (justice: $M=4.70, S D=1.82$; fair: $M=4.93, S D=1.62$; desirable: $M=4.61, S D=1.82)$ actions over other actions. They were most opposed to the less exposure (justice: $M=2.67, S D=1.73$; fair: $M=2.77, S D=1.78$; desirable: $M=2.79, S D=1.85$ ) and more exposure (justice: $M=3.34, S D=1.69$; fair: $M=3.75, S D=1.56$; desirable: $M=3.74, S D=1.72$ ) actions.

Post hoc comparisons indicated that justice, fairness, and desirability ratings of an action were not statistically significantly different from one another for the banning, offender list, own space, identity, and less exposure actions. Fairness was rated significantly more highly than justice in four conditions (and higher but not statistically significant in the other six): removing content (justice: $M=5.26, S D=1.67$; fair: $M=5.53$, 


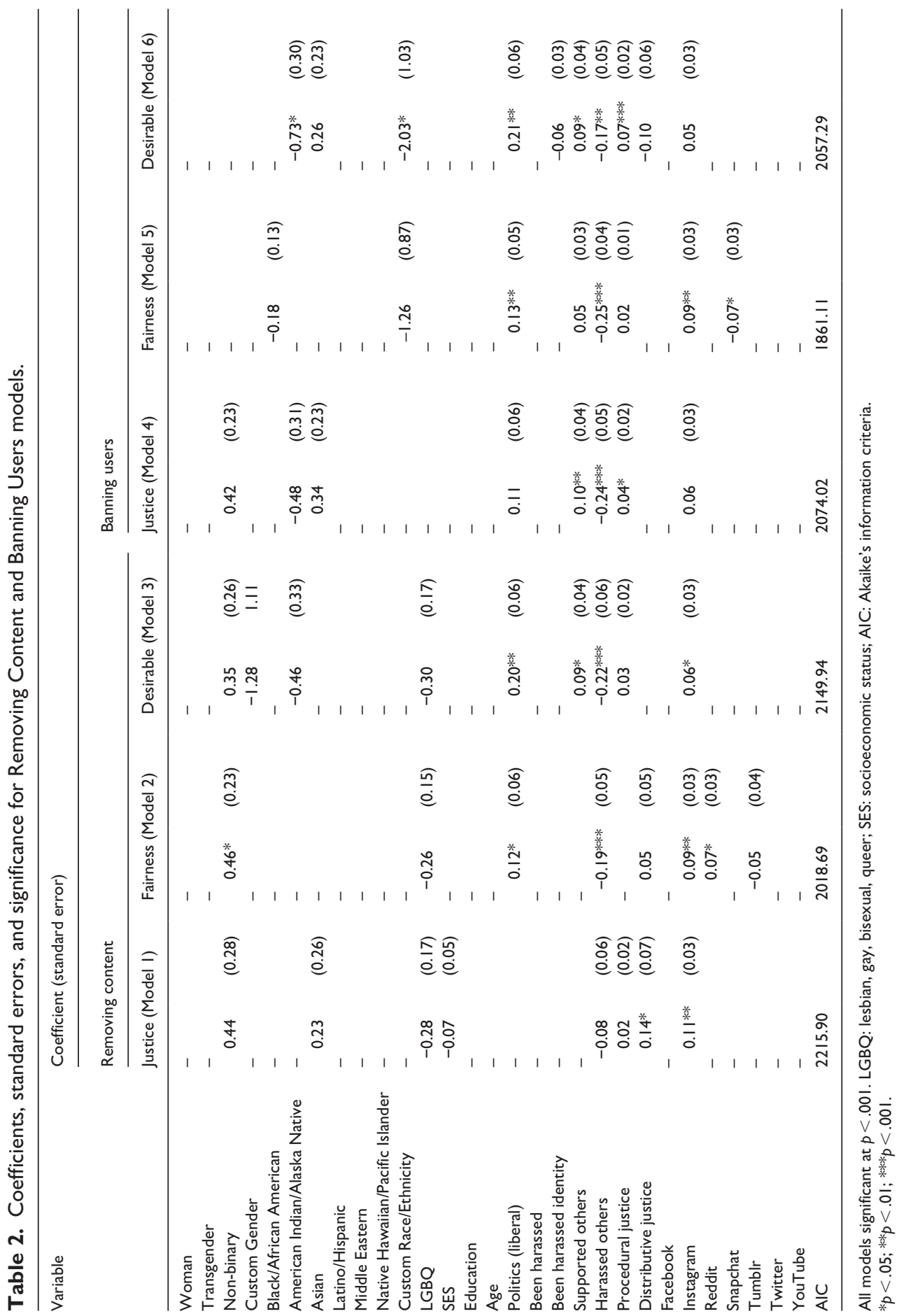




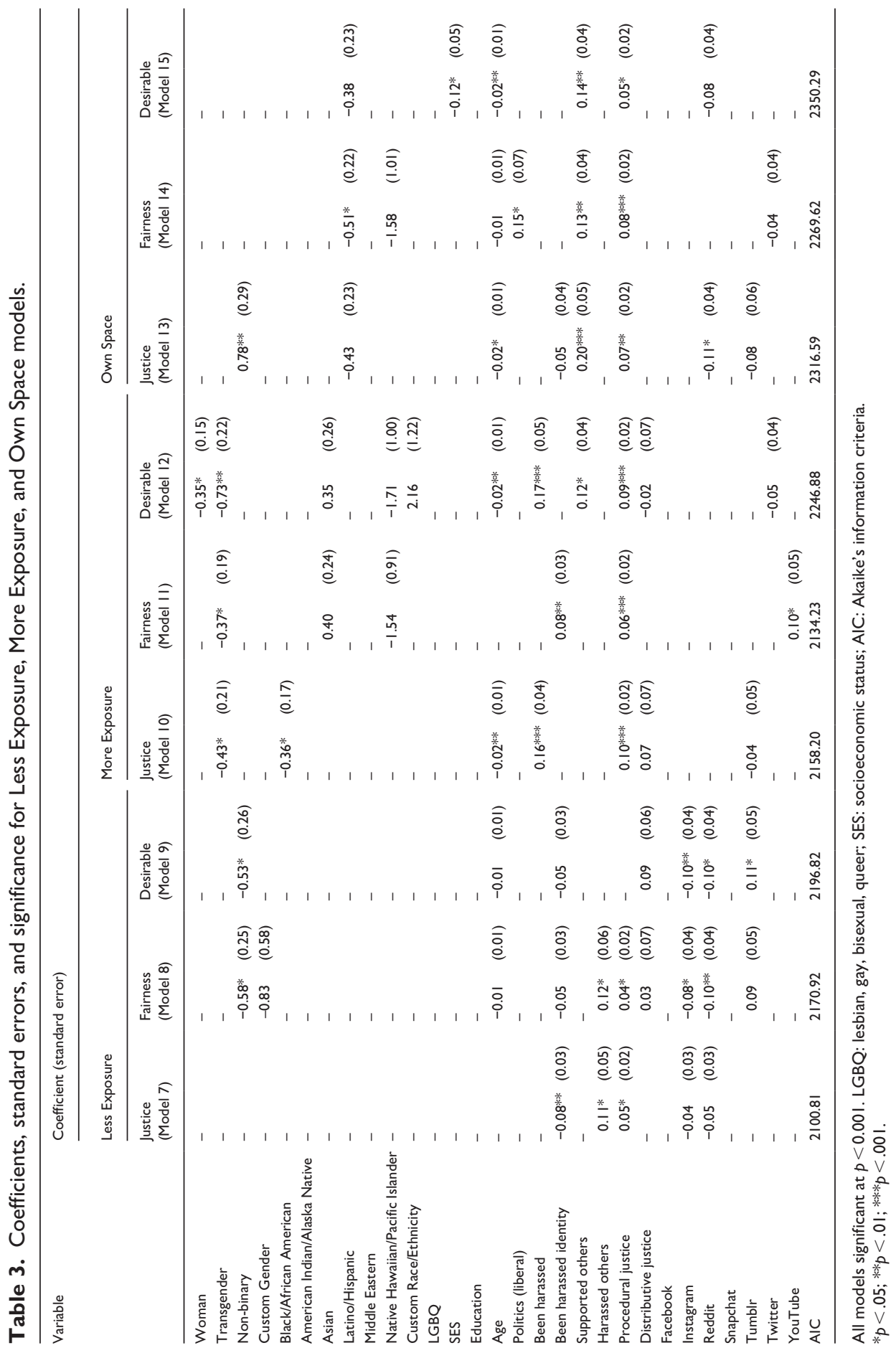




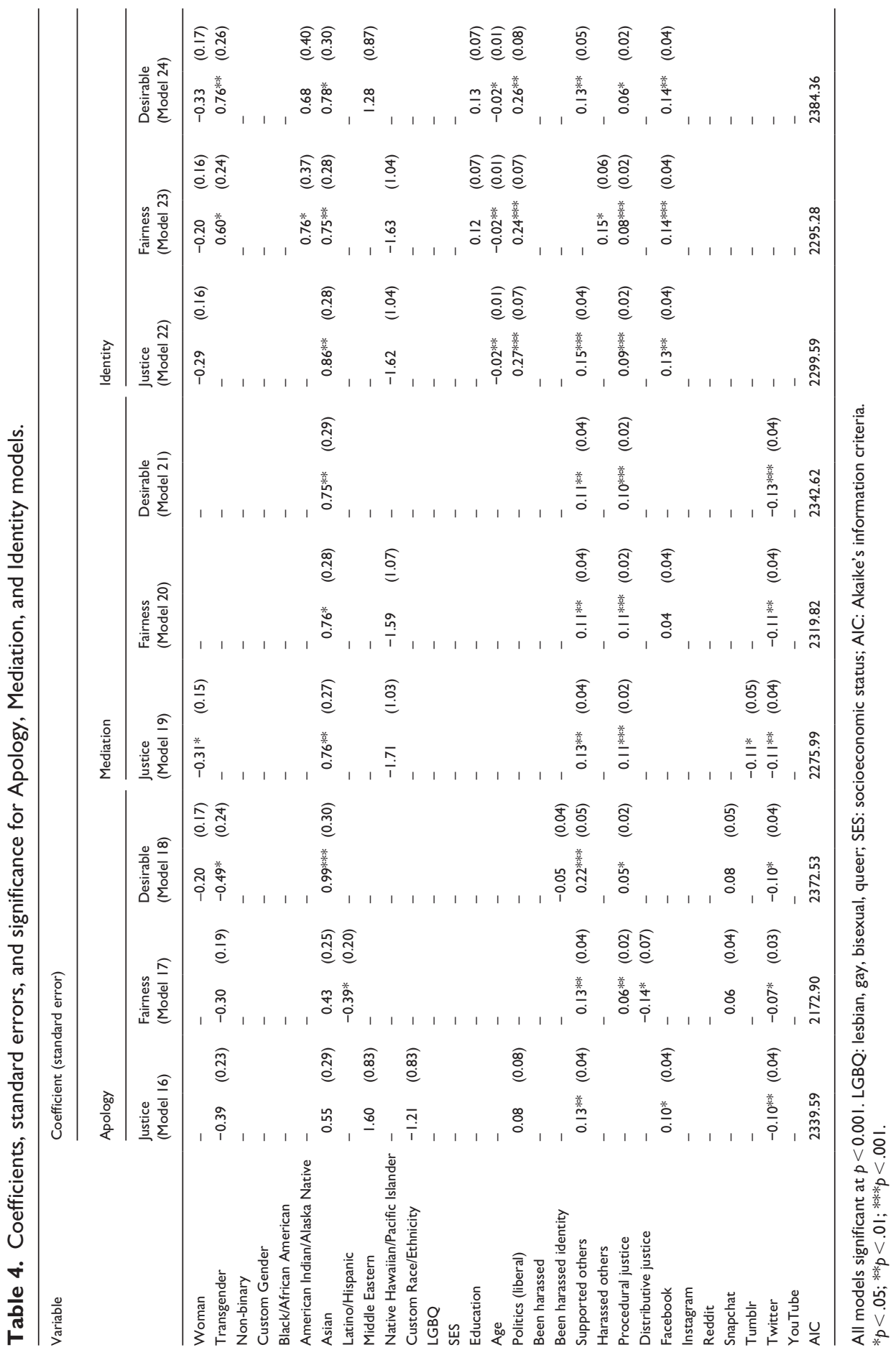




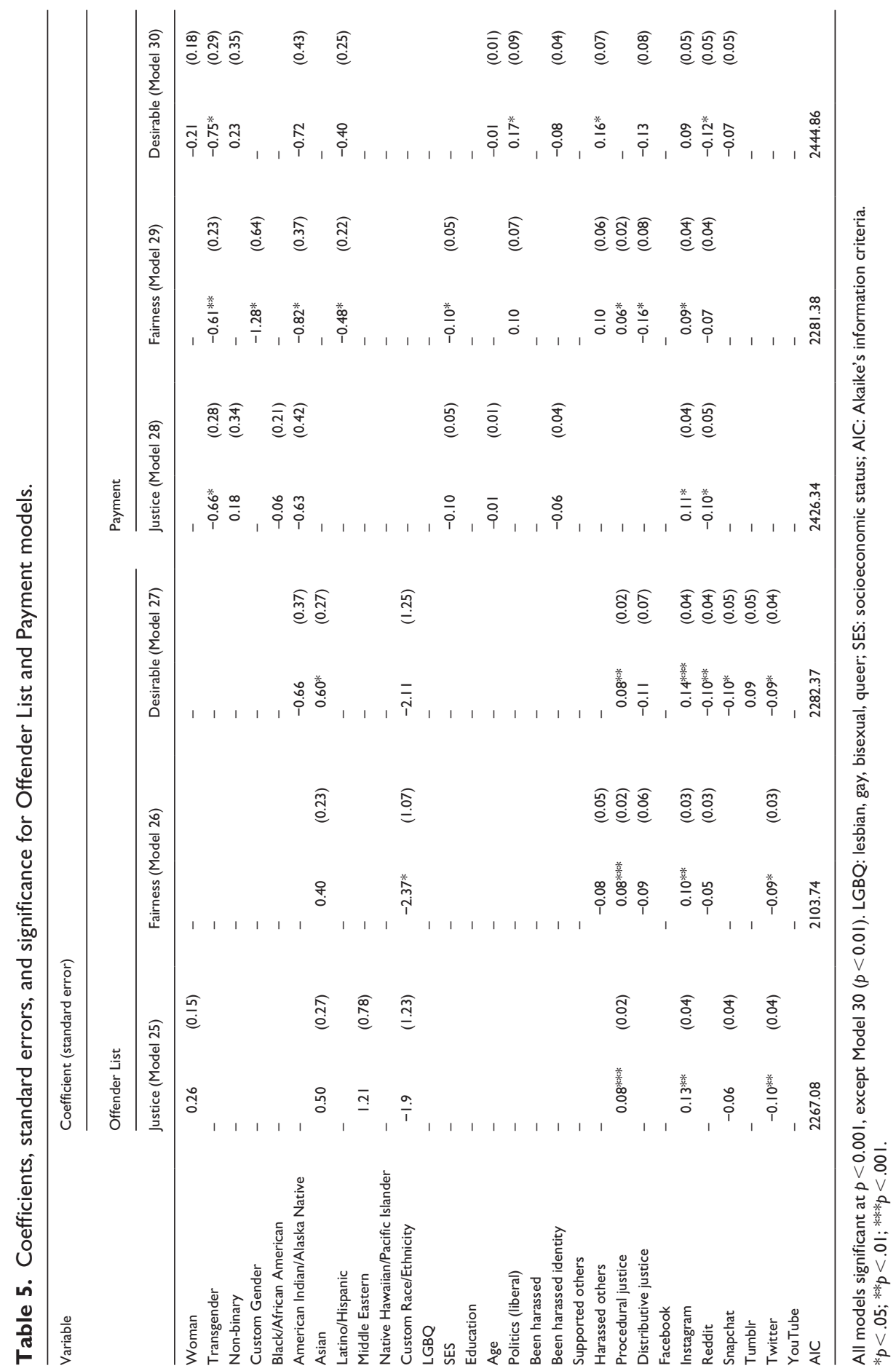




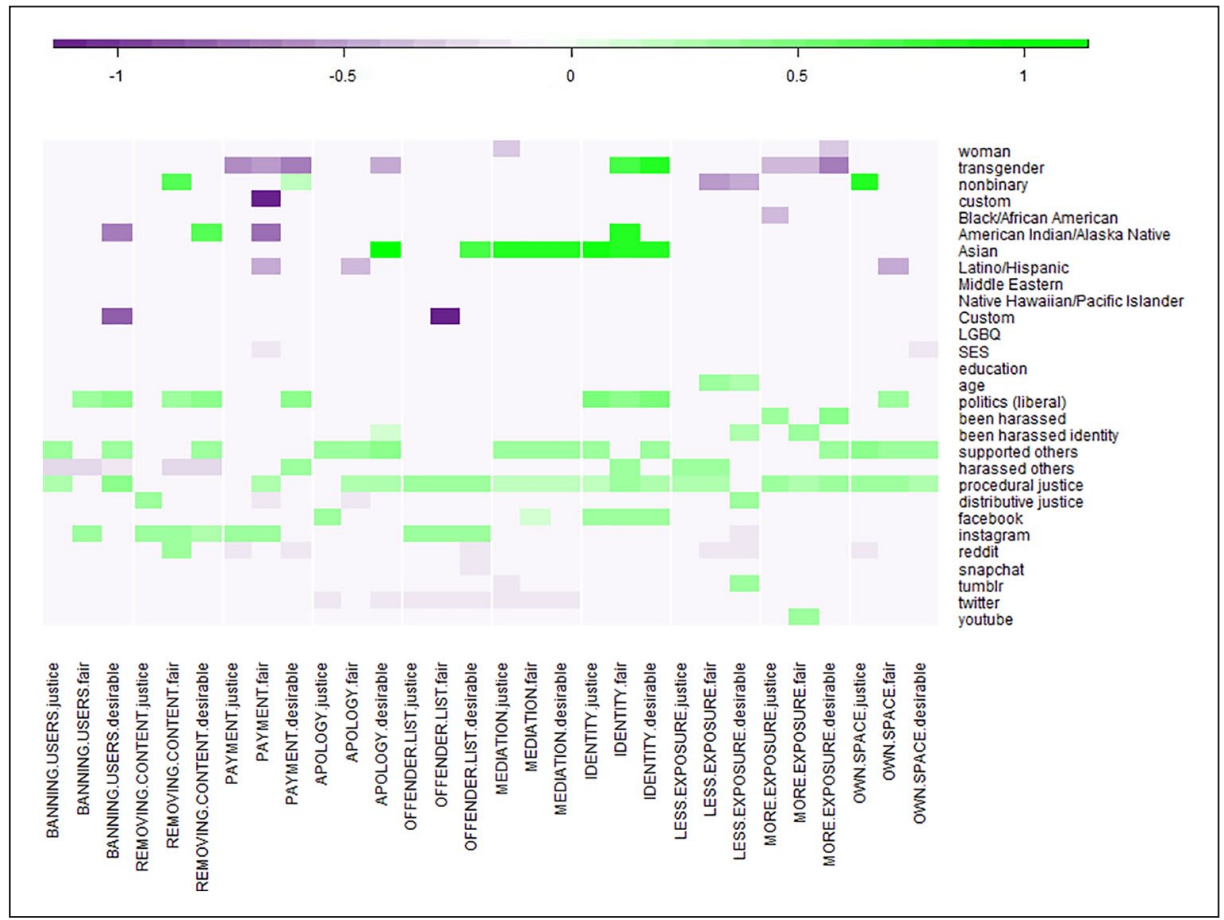

Figure 2. Heat map showing correlation coefficients of preferences for actions by independent variable (race, age, social media use, etc.).

$S D=1.50$ ), payment (justice: $M=4.15, S D=1.89$; fair: $M=4.58, S D=1.72$ ), own space (justice: $M=4.05, S D=1.79$; fair: $M=4.37, S D=1.68$ ), and more exposure (justice: $M=3.34, S D=1.69$; fair: $M=3.75, S D=1.56)$. Other actions revealed differences, for example, the payment action was significantly more desirable $(M=4.72 ; S D=1.90)$ than just $(M=4.15 ; S D=1.89)$, whereas the mediation action was significantly more fair $(M=3.78 ; S D=1.77)$ than desirable $(M=3.52 ; S D=1.92)$.

\section{Preferences by identity}

Women were significantly more likely to respond that the mediation action would not restore justice to them and that the more exposure action was undesirable (see Models 19, 12). That is, on average, women did not desire increased exposure to a large audience.

Transgender participants were significantly more likely to consider the identity action fair and desirable (Models 23, 24). However, they were less likely to favor payment on all dimensions: justice, fairness, and desirability (Models 28-30). Transgender participants were less likely to find more exposure just or desirable and considered the apology action less desirable (Models 10, 12, 18).

Non-binary participants were more likely to report that the own space action would restore justice to them and that the removing content action was fair (Models 13, 2). They were less likely to consider the less exposure action fair or desirable (Models 8, 9). 
Black participants reported the more exposure action as less just relative to White participants (Model 10). American Indian or Alaska Native participants were more likely to report the identity action to be fair, but the payment action to be unfair and the banning action to be undesirable (Models 23, 29, 6). Hispanic or Latino participants were more likely to find the payment, apology, and own space actions to be unfair (Models 29, 17, 14). Asian participants were more likely to favor the mediation and identity actions as just, fair, and desirable (Models 19-21, 22-24) and the offender list and apology as desirable (Models 27, 18).

People with a higher household income were significantly more likely to find payment to be unfair and own space to be undesirable (Models 29, 15). Neither education nor employment predicted any of the actions. Older participants were more likely to disfavor the identity actions as not just, unfair, and undesirable (Models 2-24). They also found the more exposure and own space actions not just and also undesirable (Models 10, $12,13,15)$.

Finally, liberal participants (as opposed to conservative participants) were significantly more likely to favor the identity actions as just, fair, and desirable (Models 22-24). They were more likely to find the removing content and banning actions to be fair and desirable (Models 2, 3, 5, 6), the own space action to be fair, and the payment action to be desirable (Models 14, 30).

\section{Preferences by social media use}

Instagram users were significantly more likely to consider the removing content and offender list actions as just, fair, and desirable (Models 1-3, 25-27), the payment action as just and fair (Models 28, 29), and the banning users action as fair (Model 5). They were more likely to oppose less exposure, reporting it as less fair and less desirable (Models 8, 9). Reddit users were more likely to support the removing content action as fair but opposed payment as neither just nor desirable (Models 2, 28, 30). They also were more likely to report less exposure action to be unfair and undesirable (Models 8, 9), as well as the own space action as not just and the offender list undesirable (Models 13, 27).

Twitter users were more likely to be opposed to the offender list, apology, and mediation actions, reporting each of these as less just, fair, and desirable (Models 25-27, 16 21). Facebook users were more likely to support the identity action as just, fair, and desirable (Models 22-24). They also found the apology action to be just (Model 16). Snapchat users found the offender list action to be undesirable (Model 27). YouTube users supported the more exposure action as fair (Model 11).

\section{Preferences based on prior experiences with harassment}

Participants who had been harassed themselves were more likely to support the more exposure action as just and desirable (Models 10,12), and those who had been harassed based on their identity were more likely to find the more exposure action to be fair and the less exposure action to be unjust (Models 11,7).

Participants who had supported harassment targets were significantly more likely to support the own space, apology, and mediation actions as just, fair, and desirable (Models 
13-21). They were more likely to report that the banning and identity actions were just and desirable (Models 4, 6, 22, 24). They also were more likely to report the more exposure and removing content actions as desirable (Model 12, 3).

Participants who had harassed others were significantly more likely to oppose the removing content and banning actions across all measures - justice, fairness, and desirability (Models 1-6). They also were more likely to report that the less exposure action was both just and fair, the payment action was desirable, and educating people about their identity was fair (Models 7, 8, 30, 23).

\section{Preferences by orientations toward justice}

People who reported feeling that social media sites distribute outcomes fairly after harassment (i.e. distributive justice) were significantly more likely to find the removing content action to be just, but found both the payment and apology actions to be unfair (Models 1, 29, 17). People who reported feeling that social media sites treat people fairly after harassment (i.e. procedural justice) were more likely to be supportive in general of most response options (see details in Models 4, 6-8, 10-15, 27, 29).

\section{Discussion}

\section{Apology: visibility and reparation}

The apology action was strongly supported by participants - rated highly as fair, as well as just and desirable. Social media sites requiring apologies from offenders would indicate to targets that the social media site deemed the offense to be in violation of appropriate behavior. However, while apologies evoke acceptance of responsibility and remorse in American discourse, they are notably absent from dispute resolution and legal systems in the United States (Wagatsuma and Rosett, 1986). When present in judicial processes, apologies are usually delivered in exchange for automated sentence reductions for guilty pleas (Bibas and Bierschbach, 2004). They also may invoke admission of guilt, thus increasing punishment (Scher and Darley, 1997). Social media sites could apologize to targets, which would acknowledge harms they have experienced. They could also require apologies from offenders, which might increase support and visibility for targets (which would be preferable for some groups but not others), while also enabling a gradated sanction before banning a user entirely. Although the idea of an apology is not baked into social media governance, volunteer moderators sometimes solicit apologies from offenders, or deliver apologies to targets themselves, indicating this approach's potential (Matias, 2019; Seering et al., 2019).

Open questions remain regarding how apologies should be delivered and whether they need to be genuine. Reparation requires that apologies contain specific linguistic signals, including expressions of responsibility and remorse (Scher and Darley, 1997). However, whether and how apologies restore justice and fairness to targets is likely to vary by identity. Transgender participants rated the apology as not desirable and Hispanic/ Latino participants rated it as unfair, perhaps because an ungenuine apology would be overtly harmful and would magnify discriminations those groups experience. Twitter 
Table 6. Summary of results.

Research question/hypothesis

RQI: Are there differences in attitudes toward perceived (a) justice, (b) fairness, and/or (c) desirability of traditional vs alternative actions taken by social media sites?

$\mathrm{HIa}$ [b]: Non-dominant [Dominant] social groups will be more favorable toward perceived (a) justice, (b) fairness, and/or (c) desirability of alternative [traditional] actions taken by social media sites, as opposed to traditional [alternative] actions.

RQ2-6: Is [race/ethnicity [RQ2] / gender [RQ3] / political orientation [RQ4] / socioeconomic class [RQ5] / age [RQ6]] associated with attitudes toward perceived (a) justice, (b) fairness, and/or (c) desirability of actions taken by social media sites?

RQ7: Is frequency of use associated with attitudes toward perceived (a) justice, (b) fairness, and/or (c) desirability of actions taken by social media sites?

RQ8: Are prior experiences of being harassed or harassing others on social media associated with attitudes toward perceived (a) justice, (b) fairness, and/or (c) desirability of actions taken by social media sites?

RQ9: Are orientations toward procedural or distributive justice associated with attitudes toward perceived (a) justice, (b) fairness, and/or (c) desirability of actions taken by social media sites?
Supported?

Yes. Traditional actions were generally viewed as more just, fair, and desirable than alternative actions, with a few exceptions (e.g. apology, offender list). See Figure I and Supplemental Materials.

Partially. Transgender participants were more likely to support identity action. Nonbinary participants were more likely to support own space action. American Indian or Alaskan Native participants were more likely to support identity action and less likely to support banning users. Asian participants were more likely to support identity, mediation, offender list, and apology actions. See Figure 2 and Tables 2 to 5.

Partially. Liberal participants were more likely to support banning users, removing content, identity, and own space. High SES participants were less likely to support payment and own space. Older participants were more likely to support less exposure and less likely to support identity and own space. See Figure 2, Tables 2 to 5, and the above cell.

Partially. Instagram users were more likely to support removing content and offender list but not less exposure. Twitter users were less likely to support offender list, apology, and mediation. Facebook users were more likely to support identity. See Figure 2 and Tables 2 to 5 .

Yes. Participants who had been harassed were more likely to support more exposure. Participants who had harassed others were more likely to support less exposure and identity, and less likely to support removing content. See Figure 2, Tables 2 to 5.

Yes. Participants who support distributive justice were less likely to support payment and apology. Participants who supported procedural justice were more likely to support most actions, except for removing content.

RQ: research question; SES: socioeconomic status. 
users rated the apology as neither just, fair, nor desirable, perhaps because they felt that a genuine apology is not likely to occur on Twitter, and because it could be coopted for further harassment. People who had supported harassment targets were strongly supportive of the apology, which reflects their allyship toward targets.

\section{Public shaming}

Participants rated the online offender list action as just, fair, and desirable; however, public shaming has been generally discarded in legal scholarship as subversive to human equality and dignity (Nussbaum, 2009). Shaming labels a person as bad instead of labeling the person's act as bad, thus marking a person with a degraded identity within society (Nussbaum, 2009). Shaming sanctions may further inflict their greatest weight on marginalized groups, magnifying the penalties on dignity (Nussbaum, 2009). In offline contexts in the United States, shaming has been used sporadically for low-level crimes (e.g. standing on a street corner with an affixed sign), as well as for more severe crimesnotably, sex offenses, which require listing on a public registry. However, public registries are aimed at community protection rather than punishment, and seek to strike a balance between protecting basic civil liberties as guaranteed by the Constitution and protecting the public from harm.

Participants' desire for an offender list may reflect a desire to punish offenders in the absence of visible or effective penal systems on social media (Blackwell et al., 2018). Instagram and Twitter users were more likely to rate the offender list as just, fair, and desirable - indicating a strong orientation toward public approaches to norm enforcement on those platforms. Snapchat users rated offender lists as undesirable, which reflects Snapchat's typically small, tight-knit communities (Bayer et al., 2015). Klonick (2015) raises three overarching concerns about public shaming on the Internet: it is not a calibrated or measured form of punishment, has questionable accuracy in terms of who or what it punishes, and results in an over-determined punishment with indeterminate social meaning. In other words, low cost, anonymous, instant, and easy access to the Internet has eviscerated whatever "natural" limits there were to public shaming and has served to amplify its effects (Klonick, 2015). However, online shaming can be used effectively if it shames the violation rather than the norm violator (Klonick, 2015). Social media sites could sanction behavior by making online harassment cases publicly visible, but without identifying the offender.

\section{The limitations of one-size-fits-all approaches}

Our results reveal how a one-size-fits-all approach to online harassment may fail to support some users while privileging others. For example, while banning users was popular overall, American Indian or Alaska Native participants considered banning users undesirable. This may reflect this group's cultural preference for restorative rather than retributive justice, their historical experiences of being forcibly removed from their own land (Brave Heart and DeBruyn, 1998), or their recent history of Facebook account bans due to names misaligned with the site's "real name" policies (Haimson and Hoffmann, 2016). The site action of educating other users about an individual's identity was favorable to 
some marginalized groups: participants who were transgender, American Indian or Alaska Native, and Asian. These are groups whose identities are frequently misunderstood, or even feared, in mainstream society, and who may tire of educating others about who they are and how they wish to be treated (Brave Heart and DeBruyn, 1998; James et al., 2016). Transgender, American Indian or Alaska Native, and Hispanic or Latino participants deemed payment as neither just, fair, nor desirable, despite these groups all facing substantial economic disparities in the United States (Brave Heart and DeBruyn, 1998; James et al., 2016; Patten, 2016). These groups may perceive compensation as a band-aid that overlooks and undervalues, rather than addresses, the racial, economic, or social injustices they experience. Payment may also be, again, at odds with American Indian or Alaska Native people's community-oriented rather than compensatory approaches to justice (Brave Heart and DeBruyn, 1998; Melton, 1995).

Participants who had been harassed previously were favorable to more exposure as just, fair, and desirable. This aligns with Citron's (2014) suggestion that harassment targets may benefit from more exposure on social media sites, such as receiving discounted advertising rates to clear their reputation, or dispute negative things said about them by harassers. However, some groups - transgender people, Black people, and womenfound these solutions less just and desirable. It could be that if exposed to a nonconsensual spotlight, some may wish to remove themselves from the public eye rather than gaining a larger audience. In the case of transgender people, widespread disclosure of their trans identity may render them especially vulnerable to violence and discrimination. However, non-binary participants responded differently-they felt that less exposure would be unfair and undesirable. While there is much overlap between transgender and non-binary participants, it could be that non-binary people often assert their identities (e.g. appearance, pronouns) in visibly non-binary ways and less exposure would limit those assertions.

Our results lay the groundwork for how, and why, social media sites should consider identities and social groups when determining online harassment processes and policies. Indeed, in her reflections on the US justice system's treatment of Black women, Crenshaw (1991) observed that removing differences between people overlooks their unique identities and experiences. Furthermore, rather than transcending such differences (as social media sites' mantra of neutrality might claim), one-size-fits-all approaches instead flatten intragroup differences and magnify structural inequities in experiences of justice (Crenshaw, 1991). Our work only focused on US perspectives; it is likely that a monolithic approach to governance further magnifies inequities when applied in global, crosscultural contexts.

Our arguments are thus twofold: we argue that justice should be the principled foundation on which social media governance decisions are made and that justice can be integrated into the design of social media systems. While one-size-fits-all approaches are ill-advised, particular alternative justice approaches may be useful if implemented for some social media users. For example, in the United States, while apologies are typically absent from judicial systems (Wagatsuma and Rosett, 1986), site apologies to targets of harassment could be more closely integrated into the content moderation process via a combination of automated and human processes. Other approaches, like payment, align with existing social norms and technological infrastructures on sites like Instagram and 
could similarly be integrated into governance processes. This work was motivated by the concern that criminal justice approaches in the United States are limited in their ability to reform offenders, and exacerbate inequities based on identity. We aim to inspire reflection and action into the merits of some criminal justice approaches, and the possibilities opened up by alternative justice theories, to support targets online.

\section{Conclusion and future work}

This study presents a broad range of social media site responses to online harassment and considers their potential for supporting targets. We put forth a theoretical argument for the limitations of the criminal justice models for supporting targets, and consider alternative approaches that recognize systematic and structural power imbalances. Our study focused only on US perspectives which represents a narrow slice of global social media use; future work in other regions of the world could bring alternative, promising approaches to justice and social media governance. Future work could also examine how participants across cultures interpret the concepts of justice and fairness. An additional limitation is that the current study did not test efficacy of proposed solutions. In some cases, like mediation, people may not like the idea in theory but may find it restorative in practice. Our study intentionally focused on approaches favored by online harassment targets, because they have been overlooked to date. As a result, we did not measure attitudes toward what may be best for the offender or for the community. If we had measured morality or dignity for all involved parties, we might observe reduced support for some approaches, like offender lists, which can indiscriminately penalize offenders.

Social media sites want to present themselves as neutral arbiters of online content (Gillespie, 2010); however, arbitration procedures can differentially impact social media users based on their individual identities and experiences. Our results indicate opportunities for developing alternative theories and approaches to supporting targets with more just, fair, and desirable responses to online harassment.

\section{Funding}

The author(s) disclosed receipt of the following financial support for the research, authorship, and/ or publication of this article: This material is based upon work supported by the National Science Foundation under Grand No. 1763297.

\section{ORCID iD}

Sarita Schoenebeck (iD https://orcid.org/0000-0002-8688-1595

\section{Supplemental material}

Supplemental material for this article is available online.

\section{Notes}

1. Preregistration: https://osf.io/ja4d8/?view_only=1bccdbff142a4257b4f92cf4d9032713

2. Most non-binary participants also considered themselves transgender $(n=30)$, while some did $\operatorname{not}(n=13)$. 


\section{References}

Ahmed S (2012) On Being Included: Racism and Diversity in Institutional Life. Durham, NC: Duke University Press.

Barocas S, Hardt M and Narayanan A (2019) Fairness and machine learning. Available at: https:// fairmlbook.org/ (accessed 26 August 2019).

Bayer J, Ellison NB, Schoenebeck SY, et al. (2015) Sharing the small moments: ephemeral social interaction on Snapchat. Information, Communication \& Society 19(7): 956-977.

Bell D (2008) And We Are Not Saved: The Elusive Quest for Racial Justice. New York: Basic Books.

Bibas S and Bierschbach RA (2004) Integrating remorse and apology into criminal procedure essay. The Yale Law Journal 114: 85-148.

Blackwell L, Chen T, Schoenebeck S, et al. (2018) When online harassment is perceived to be justified. In: The 12th international AAAI conference on web and social media (ICWSM 2018), Palo Alto, CA, 25-28 June. Menlo Park, CA, AAAI Press.

Blackwell L, Dimond J, Schoenebeck S, et al. (2017) Classification and its consequences for online harassment: design insights from HeartMob. Proceedings of ACM on Human-Computer Interaction 1: 1-19.

Bobo LD and Thompson V (2006) Unfair by design: the war on drugs, race, and the legitimacy of the criminal justice system. Social Research: An International Quarterly 73(2): 445-472.

Bradford B, Grisel F, Meares TL, et al. (2019) Report of the Facebook Data Transparency Advisory Group. New Haven, CT: Yale Law School.

Braithwaite J (1999) Restorative justice: assessing optimistic and pessimistic accounts. Crime and Justice 25: 1-127.

Brave Heart MY and DeBruyn LM (1998) The American Indian Holocaust: healing historical unresolved grief. American Indian and Alaska Native Mental Health Research: Journal of the National Center 8(2): 56-78.

Cai J and Wohn DY (2019) What are effective strategies of handling harassment on twitch? Users' perspectives. In: Conference companion publication of the 2019 on computer supported cooperative work and social computing, pp. 166-170. Available at: https://dl.acm.org/ doi/10.1145/3311957.3359478

Caplan R (2018) Content or Context Moderation? Artisanal, Community-Reliant, and Industrial Approaches. New York: Data \& Society.

Chandrasekharan E, Gandhi C, Mustelier MW, et al. (2019) Crossmod: a cross-community learning-based system to assist Reddit moderators. In: Proceedings of the ACM on human-computer interaction. 3, CSCW, Article 174 (November 2019), p. 30. Available at: https://dl.acm. org/doi/10.1145/3359276

Citron DK (2014) Hate Crimes in Cyberspace. Cambridge, MA: Harvard University Press.

Clayton S and Opotow S (2003) Justice and identity: changing perspectives on what is fair. Personality and Social Psychology Review 7(4): 298-310.

Coates TN (2014) The case for reparations. The Atlantic 313(5): 54-71.

Cole D (1999) No equal justice: race and class in the American criminal justice system. Available at: https://www.ncjrs.gov/App/abstractdb/AbstractDBDetails.aspx?id=179184

Crenshaw K (1991) Mapping the margins: intersectionality, identity politics, and violence against women of color. Stanford Law Review 43(6): 1241-1299.

D'Ignazio C and Klein L (2020) Data Feminism. Cambridge, MA: MIT Press.

Duggan M (2017) Online harassment 2017, 11 July. Available at: http:/www.pewinternet. org/2017/07/11/online-harassment-2017/ (accessed 17 September 2018).

Fallon RH and Weiler PC (1984) Firefighters v. Stotts: conflicting models of racial justice. The Supreme Court Review 1984: 1-68. 
Gillespie T (2010) The politics of “platforms." New Media \& Society 12(3): 347-364.

Gillespie T (2018) Custodians of the Internet: Platforms, Content Moderation, and the Hidden Decisions that Shape Social Media. New Haven, CT; London: Yale University Press.

Haimson OL and Hoffmann AL (2016) Constructing and enforcing "authentic" identity online: Facebook, real names, and non-normative identities. First Monday 21(6).

Hoffmann AL (2019) Where fairness fails: data, algorithms, and the limits of antidiscrimination discourse. Information, Communication \& Society 22(7): 900-915.

Hoffmann AL and Jonas A (2016) Recasting justice for internet and online industry research ethics. In: Zimmer M and Kinder-Kuranda K (eds) Internet Research Ethics for the Social Age: New Cases and Challenges. Available at: https://papers.ssrn.com/abstract=2836690

Jackson TF (2013) From Civil Rights to Human Rights: Martin Luther King, Jr., and the Struggle for Economic Justice. Philadelphia, PA: University of Pennsylvania Press.

James S, Herman J, Rankin S, et al. (2016) The report of the 2015 U.S. Transgender Survey. Available at: https://ncvc.dspacedirect.org/handle/20.500.11990/1299

Jhaver S, Appling DS, Gilbert E, et al. (2019) "Did you suspect the post would be removed?" Understanding user reactions to content removals on Reddit. In: Proceedings of ACM on human-computer interaction. 3, CSCW, Article 192 (November 2019), p. 33. Available at: https://dl.acm.org/doi/10.1145/3359294

Jhaver S, Ghoshal S, Bruckman A, et al. (2018) Online harassment and content moderation: the case of blocklists. ACM Transactions on Computer-Human Interaction 25(2): 1-33.

Klonick K (2015) Re-shaming the debate: social norms, shame, and regulation in an internet age. Maryland Law Review 75: 1029-1065.

Laloggia J Inquiries (2019) U.S. public has little confidence in social media companies to determine offensive content. Available at: https://www.pewresearch.org/fact-tank/2019/07/11/ u-s-public-has-little-confidence-in-social-media-companies-to-determine-offensive-content/

Massanari A (2017) \#Gamergate and The Fappening: how Reddit's algorithm, governance, and culture support toxic technocultures. New Media \& Society 19(3): 329-346.

Matias JN (2019) The civic labor of volunteer moderators online. Social Media + Society 5(2): 2056305119836778.

Matias JN, Johnson A, Boesel WE, et al. (2015) Reporting, Reviewing, and Responding to Harassment on Twitter. SSRN Scholarly Paper No. ID 2602018. Available at: https://papers. ssrn.com/abstract $=2602018$

Melton AP (1995) Indigenous justice systems and tribal society. Indian tribal courts and justice: a symposium. Judicature 79: 126-133.

Munger K (2017) Tweetment effects on the tweeted: experimentally reducing racist harassment. Political Behavior 39(3): 629-649.

Nelson A (2016) The Social Life of DNA: Race, Reparations, and Reconciliation After the Genome. Boston, MA: Beacon Press.

Nussbaum MC (2009) Hiding from Humanity: Disgust, Shame, and the Law. Princeton, NJ: Princeton University Press.

Pater JA, Kim MK, Mynatt ED, et al. (2016) Characterizations of online harassment: comparing policies across social media platforms. In: Proceedings of the 19th international conference on supporting group work, Sanibel Island, FL, 13-16 November, pp. 369-374. New York: The Association for Computing Machinery.

Patten E (2016) Racial, gender wage gaps persist in U.S. despite some progress. Available at: https:// www.pewresearch.org/fact-tank/2016/07/01/racial-gender-wage-gaps-persist-in-u-s-despitesome-progress/

Postigo H (2016) The socio-technical architecture of digital labor: Converting play into YouTube money. New Media \& Society 18(2): 332-349. 
Rawls J (2009) A Theory of Justice. Cambridge, MA: Harvard University Press.

Roberts S (2019) Behind the screen: content moderation in the shadows of social media. Available at: https://www.amazon.com/Behind-Screen-Content-Moderation-Shadows/dp/0300235887

Scher SJ and Darley JM (1997) How effective are the things people say to apologize? Effects of the realization of the apology speech act. Journal of Psycholinguistic Research 26(1): 127-140.

Seering J, Wang T, Yoon J, et al. (2019) Moderator engagement and community development in the age of algorithms. New Media \& Society 21(7): 1417-1443.

Sunshine J and Tyler TR (2003) The role of procedural justice and legitimacy in shaping public support for policing. Law \& Society Review 37(3): 513-548.

The Combahee River Collective Statement (n.d.) Available at: http://circuitous.org/scraps/combahee.html

Tyler TR (1994) Psychological models of the justice motive: antecedents of distributive and procedural justice. Journal of Personality and Social Psychology 67(5): 850-863.

Wagatsuma H and Rosett A (1986) The implications of apology: Law and culture in Japan and the United States. Law \& Sociology Review 20: 461.

Wenzel M, Okimoto TG, Feather NT, et al. (2008) Retributive and restorative justice. Law and Human Behavior 32(5): 375-389.

Wohn DY (2019) Volunteer moderators in Twitch micro Communities: how they get involved, the roles they play, and the emotional labor they experience. In: Proceedings of the $2019 \mathrm{CHI}$ conference on human factors in computing systems (CHI'19). ACM, New York, Paper 160, p. 13. Available at: https://dl.acm.org/doi/10.1145/3290605.3300390

Zehr H (2015) The Little Book of Restorative Justice: Revised and Updated. New York: Simon \& Schuster.

\section{Author biographies}

Sarita Schoenebeck is an associate professor in the School of Information at the University of Michigan. Her research explores the study and design of social computing systems, with a focus on justice and equity in online contexts.

Oliver L Haimson is an assistant professor at the University of Michigan School of Information. His research interests include marginalized individuals and communities' social media behaviors, and transgender identities and experiences online.

Lisa Nakamura is the Gwendolyn Calvert Baker Collegiate Professor of American Culture and the Director of the Digital Studies Institute at the University of Michigan. She works on virtual reality and toxic embodiment, women of color and how they create and maintain the Internet. 